\title{
The Interaction Between MiR-141 and IncRNA-H19 in Regulating Cell Proliferation and Migration in Gastric Cancer
}

\author{
Xiaoying Zhou ${ }^{a, b}$ Feng Ye ${ }^{a}$ Chengqiang Yin ${ }^{a, b}$ Ya Zhuang ${ }^{a, b}$ Ge Yue $e^{a, b}$ \\ Guoxin Zhanga,b \\ aDepartment of Gastroenterology, First Affiliated Hospital of Nanjing Medical University, Nanjing, \\ ${ }^{b}$ First Clinical Medical College of Nanjing Medical University, Nanjing China
}

\section{Key Words}

H19 • MiR-141 • Proliferation • Migration • Gastric cancer

\begin{abstract}
Background/Aims: Non-coding RNAs including miRNA and IncRNA had been reported to regulate gene expression and were both related to cancer progression. MicroRNA-141 (miR141) has been reported to play a role in the epithelial to mesenchymal transition (EMT) process and $\mathrm{H} 19$ has also been demonstrated to promote malignancy in various cancers. We aimed to determine the correlation between miR-141 and $\mathrm{H} 19$ and their roles in gastric cancer in this study. Methods: H19 and miR-141 expression were detected by qRT-PCR. By bioinformatic analysis and luciferase assay, we examined the correlation between $\mathrm{H} 19$ and miR-141 in vitro. Results: $\mathrm{H} 19$ expression was found to be inversely correlated to miR-141 expression in gastric cancer cells and tissues. $\mathrm{H} 19$ promotes malignancy including proliferation and invasion whereas miR-141 suppresses malignancy in human cancer cells. MiR-141 binds to $\mathrm{H} 19$ in a sequence specific manner, and suppresses $\mathrm{H} 19$ expression and functions including proliferation and invasion. MiR-141 could also regulate H19 target genes and miR-141 inhibitor restores H19 siRNA function, while H19 regulates miR-141 target gene ZEB1. Conclusion: These results were the first to demonstrate that $\mathrm{H} 19$ and miR-141 could compete with each other and affect their target genes in gastric cancer, which provide important clues for understanding the key roles of IncRNA-miRNA functional network in cancer.
\end{abstract}

X. Zhou, F. Ye and C. Yin contributed equally to the work. 


\section{Cellular Physiology Cell Physiol Biochem 2015;36:1440-1452 \begin{tabular}{ll|l} 
and Biochemistry & $\begin{array}{l}\text { DOI: 10.1159/000430309 } \\
\text { Publisned onlne: July 06, } 2015\end{array}$ & $\begin{array}{l}\text { ○ 2015 S. Karger AG, Basel } \\
\text { www.karger.com/cpb }\end{array}$ \\
\hline
\end{tabular} \\ Zhou et al.: MiR-141 and H19 Regulation in GC}

\section{Introduction}

Non-coding RNAs (ncRNAs) have been demonstrated to have important roles in gene regulation and a large number of ncRNAs have been discovered [1]. They have been found to be important regulators of gene expression in development, physiology, and, when dysfunctional, in the presence of disease [2]. This variegated class of RNA species encompasses the well-known miRNAs, as well as the most recently acknowledged IncRNAs. MiRNAs have been intensively studied and much is now known about their biological functions; IncRNAs constitutes a new, potentially fascinating, territory to be explored yet $[3,4]$. Poliseno [5] previously proposed a competing endogenous RNA (ceRNA) hypothesis, which was supported by numerous evidences. In a recent paper, Paci et al. [6] proposed a computational analysis able to identify ceRNA interactions between long non-coding RNAs and messenger RNAs in human breast cancer. The model described a complex post-transcriptional regulatory network mediated by miRNAs: by sharing one or more miRNA response elements (MRE), protein-coding and non-coding RNAs compete for binding to miRNAs and then regulate each other's expression. They demonstrated the existence of ceRNA interaction among mRNAs in vitro and in vivo. Sumazin analyzed gene expression data in glioblastoma, and found more than 7,000 transcripts acting as ceRNAs [7]. Linc-MD1, a long non-coding RNA (lncRNA), regulates myoblast differentiation by competing for binding to miR-133 and miR-135 [8]. The above studies showed a new layer of post-transcriptional regulation.

Gastric cancer (GC) is the fourth most common cancer and the second leading cause of cancer-related death worldwide [9]. Despite advances in surgery and other treatment modalities, the prognosis of GC patients remains poor because of the advanced stage of the disease at the time of diagnosis [10]. Therefore, it is imperative to elucidate the regulatory network underlying gastric carcinogenesis to develop novel biomarkers for diagnosis and targeted therapy. $\mathrm{H} 19$ is reported to be significantly up-regulated in GC and its overexpression could promote cell invasiveness and to increase proliferation, cell cycle progression and reduced apoptosis [11]. The miRNA-200 family (including miR-200a, miR-200b, miR-200c, miR-141 and miR-429) was previously shown to inhibit ZEB1 and up-regulate E-cadherin, indicating that the miRNA-200 family plays a role in the epithelial to mesenchymal transition (EMT) process [12]. The expression of miR-141 is reported to be down-regulated in GC [13] and up-regulated in epithelial ovarian cancer [14], which differs from different tumors and cell types. However, the relation between H19 and miR-141 has never been investigated. In this study, we found that miR-141 and H19 were negatively correlated with each other. H19 could compete for miR-141 binding with their targets and vice versa, which contributed significantly to GC progression.

\section{Materials and Methods}

\section{Patient samples}

Fifteen patients with GC and paired adjacent histologically normal tissues were included in the study. We obtained the informed consent from all the patients and the approval of the study from the Institutional Review Board of the first affiliated hospital of Nanjing medical university.

\section{Cell culture and transfection}

GC MKN45 and 7901 cells, GES-1 cells were purchased from American Type Culture Collection (Manassas, VA). Cells were cultured in 1640 (Gibico) plus 10\% fetal bovine serum. Cisplatin was purchased from Sigma-Aldrich (St Louis, MO). Cisplatin was dissolved in DMSO and added to cells at a final concentration of $10 \mu \mathrm{g} / \mathrm{ml}$. Has-miR-141 mimic or inhibitor or their respective scramble controls were from Genepharma (Shanghai, China). H19 siRNA or vector were from Invitrogen (Carlsbad, CA).

Cells were transfected using transfection reagent Lipofectamine 2000 (Invitrogen) according to the protocol. They were harvested $48 \mathrm{~h}$ after transfection. For co-transfection, cells were initially transfected with NC or mimics using Lipofectamine 2000 (Invitrogen), according to the manufacturer's instructions. 


\section{Cellular Physiology Cell Physiol Biochem 2015;36:1440-1452 \begin{tabular}{ll|l} 
and Biochemistry & $\begin{array}{l}\text { DOI: 10.1159/000430309 } \\
\text { Publisned onlnne: July 06, } 2015\end{array}$ & $\begin{array}{l}\text { ( ) 2015 S. Karger AG, Basel } \\
\text { www.karger.com/cpb }\end{array}$ \\
\hline
\end{tabular}}

Zhou et al.: MiR-141 and H19 Regulation in GC

Subsequently, the cells were transfected with siRNA control or H19 siRNA using Lipofectamine 2000, according to the manufacturer's instructions. The sequences of mimics or siRNAs were listed in Table 1.

\section{Cell proliferation assay}

Cell proliferation was measured using MTT assay. Cells were seeded in a 96-well plate and cultured in normal medium. At 0, 24, 48 and $72 \mathrm{~h}$ after transfection, the cells were incubated in $0.1 \mathrm{mg} / \mathrm{ml} \mathrm{MTT}$ at $37^{\circ} \mathrm{C}$ for $4 \mathrm{~h}$ and lysed in dimethyl sulfoxide (DMSO) at room temperature for $10 \mathrm{~min}$. The absorbance in each well was measured by a microplate reader (Bio-Rad, Hercules, CA, USA). Data are the mean \pm standard deviation (SD) of 3 independent experiments.

\section{Cell apoptosis assay}

Apoptosis was measured using flow cytometry (Cell Lab Quanta SC, Beckman Coulter, Brea, CA) with AnnexinV-FITC labeling. Measurements were repeated independently three times.

\section{Invasion assay}

Culture inserts of 8- $\mu \mathrm{m}$ pore size (Transwell; Costar) were coated with Matrigel (BD Biosciences, San Jose) (100 ug per well) and placed into the wells of 24-well culture plates. In the lower chamber, $500 \mathrm{ul}$ of 1640 containing $10 \%$ FBS was added and $1 \times 10^{5}$ cells were seeded to the upper chamber. After 36 hours of incubation at $37^{\circ} \mathrm{C}$ with $5 \% \mathrm{CO}_{2}$, the number of cells that had migrated through the pores were fixed with $10 \%$ formalin and stained with $0.05 \%$ Crystal Violet. Crystal Violet was solubilized with methanol and absorbance at $540 \mathrm{~nm}$ was measured by a kinetic microplate reader (Spectra MAX 190; Molecular Devices Co., Sunnyvale, CA). Data are the mean \pm S.D. of 3 independent experiments.

RNA extraction and Quantitative RT-PCR

RNA was extracted from cells after transfected using TRIzol (Invitrogen) following the manufacturer's protocol. To detect the levels of miR-141 in cells, reverse transcription (RT) was conducted with the Applied Biosystems $^{\mathrm{R}}$ TaqMan $^{\mathrm{R}}$ MicroRNA

Reverse Transcription Kit (Applied Biosystems, Foster City, CA). The primers for the miR-141 were purchased from Guangzhou Ribo BioCoLTD (Guangzhou, China). U6 was used for normalization. The ABI

Table 1. Sequences of primers and siRNA used in this study

\begin{tabular}{lll}
\hline Name & Sequences & \\
\hline qPCR primers & & \\
miR-141 & Sense & 5'-GGGCATCTTCCAGTACAGT-3' \\
& Anti-sense & 5'-CAGTGCGTGTCGTGGAGT-3' \\
H19 & Sense & 5'-CCCACAACATGAAAGAAATGGTGC-3' \\
& Anti-sense & 5'-CACCTTCGAGAGCCGATTCC-3' \\
Igf1r & Sense & 5'-AGGATATTGGGCTTTACAACCTG-3' \\
& Anti-sense & 5'-GAGGTAACAGAGGTCAGCATTTT-3' \\
Igf2 & Sense & 5'-GTGGCATCGTTGAGGAGTG-3' \\
& Anti-sense & 5'-CACGTCCCTCTCGGACTTG-3' \\
miR-675 & Sense & 5'-GGGTGGTGCGGAGAGGGCCC-3' \\
& Anti-sense & 5'-CAGTGCGTGTCGTGGAGT-3' \\
ZEB1 & Sense & 5'-GATGATGAATGCGAGTCAGATGC-3' \\
& Anti-sense & 5'-ACAGCAGTGTCTTGTTGTTGT-3' \\
siRNA and mimic sequences & \\
H19 siRnA & Sense & 5'-CCCACAACAUGAAAGAAAUTT-3' \\
& Anti-sense & 5'-AUUUCUUUCAUGUUGUGGGTT-3' \\
miR-141 inhibitor & & CCAUCUUUACCAGACAGUGUUA \\
& & \\
miR-141 mimic & Sense & 5'-UAACACUGUCUGGUAAAGAUGG-3' \\
& Anti-sense & 5'-AUCUUUACCAGACAGUGUUAUU-3' \\
\hline
\end{tabular}




\section{Cellular Physiology Cell Physiol Biochem 2015;36:1440-1452 \begin{tabular}{l|l} 
and Biochemistry $\begin{array}{l}\text { DOI: 10.1159/000430309 } \\
\text { Publisned onlnne: July 06, } 2015\end{array}$ & $\begin{array}{l}\text { ( ) 2015 S. Karger AG, Basel } \\
\text { www.karger.com/cpb }\end{array}$ \\
\hline
\end{tabular} \\ Zhou et al.: MiR-141 and H19 Regulation in GC}

StepOne Plus (Applied Biosystems, Foster City, CA) was used to perform the amplification reaction. And the date was analyzed by the $2^{-\Delta \Delta C t}$ method. The sequences of primers were also listed in Table 1 .

\section{Western blot analysis}

Proteins were extracted from cells with RIPA lysis buffer (KenGEN, China) and were quantified using a BCA Protein Assay Kit (Thermo, USA). We add the 30mg of protein lysates to SDS-PAGE. The electrophoresed proteins were transferred to PVDF membranes (Millipore, USA). The membrane was blocked in 5\% nonfat milk and incubated with diluted antibodies against ZEB1 (1:1000; CST; USA), Igf1r (1:1000; CST; USA) and Igf2 (1:1000; CST; USA), followed by incubation with a horseradish peroxidase-conjugated secondary antibody (1:5000; Santa Cruz; USA). $\beta$-actin was used as a control (1:1000, CST, USA).

\section{Dual luciferase reporter assay}

The fragment from H19 containing the predicted hsa-miR-141 binding site were chemically synthesized and cloned into the Xhol and Notl sites of the pGL3 vector, respectively. The resulted vectors were called the reporter vector H19-wild type (WT). The corresponding mutants were created by mutating the hsa-miR-141 seed region binding site, which were called the reporter vector H19-mutated-type (MUT).

Hsa-miR-141 mimic or negative control mimic was co-transfected with the reporter vectors containing either the targeting sequences or the corresponding mutants using Transfection reagent (Invitrogen) according to the protocol. Luciferase activity was assayed $48 \mathrm{~h}$ after transfection, using a dual luciferase reporter assay system (Promega).

\section{Statistical analysis}

The expression differences between GC and matched normal tissues were analyzed using paired samples t-test. Pearson's coefficient correlation was used for expression correlation assay. MTT assays were analyzed using ANOVA. The statistical analyses were performed using SPSS (Version 17.0). P values were two-sided and a value of $<0.05$ was considered to be statistically significant.

\section{Results}

Inverse expression of $H 19$ and miR-141 in GC cells and tissues

Real-time PCR revealed that compared with normal tissues, tumors exhibited a significantly lower miR-141 expression (Fig. 1A) and a significantly higher H19 expression (Fig. 1B). Pearson expression analysis suggested that an inverse relationship between miR-141 and H19 expression in tumors (Fig. 1C, $\mathrm{r}=-0.969, \mathrm{p}=0.000$ ). In vitro, miR-141 was significantly lower expressed in SGC-7901 and MKN45 compared with non-malignant GES-1 cells (Fig. 1D), while H19 was significantly higher expressed (Fig. 1E).

Cisplatin (DDP) is a kind of chemotherapy drugs and has been reported to inhibit NF$\mathrm{kB}$ and Akt signaling pathways to induce cell apoptosis and inhibit cell proliferation. To investigate the effects of cisplatin on H19 and miR-141, we treated SGC-7901 and MKN45 cells with $10 \mathrm{ug} / \mathrm{ml}$ cisplatin for 48 hours. Cisplatin treatment decreased H19 expression and increased miR-141 expression (Fig. 1F-I), indicating that it had opposing effects on their expression. We also examined other miRNAs which frequently dysregulated in GC. The results showed that miR-223 and miR-101 was significantly changed upon cisplatin treatment. However, no correlation was found between miR-223 or miR-101 with H19 (data not shown).

\section{Antagonistic effect of $H 19$ and miR-141 on cell proliferation and invasion}

To study the effect of H19 on the proliferation and invasion of GC cells, we transiently transfected 7901 cells with H19 siRNA or control. Transfection of H19 siRNA decreased H19 levels in GC cells (Fig. 2A). MTT assays showed that H19 siRNA inhibited proliferation of 7901 and MKN45 cells by about 50\% at $96 \mathrm{~h}$ (Fig. 2B). These results indicated that $\mathrm{H} 19$ strongly promotes cell proliferation. We also transiently transfected these cells with negative control or miR-141 mimics and studied the effect of miR-141 on the growth of 7901 and MKN45 


\section{Cellular Physiology Cell Physiol Biochem 2015;36:1440-1452 \begin{tabular}{l|l} 
DOI: 10.1159/000430309 & o 2015 S. Karger AG, Basel
\end{tabular} and Biochemistry Publisned onाne: July U6, 2015 www.karger.com/cpb
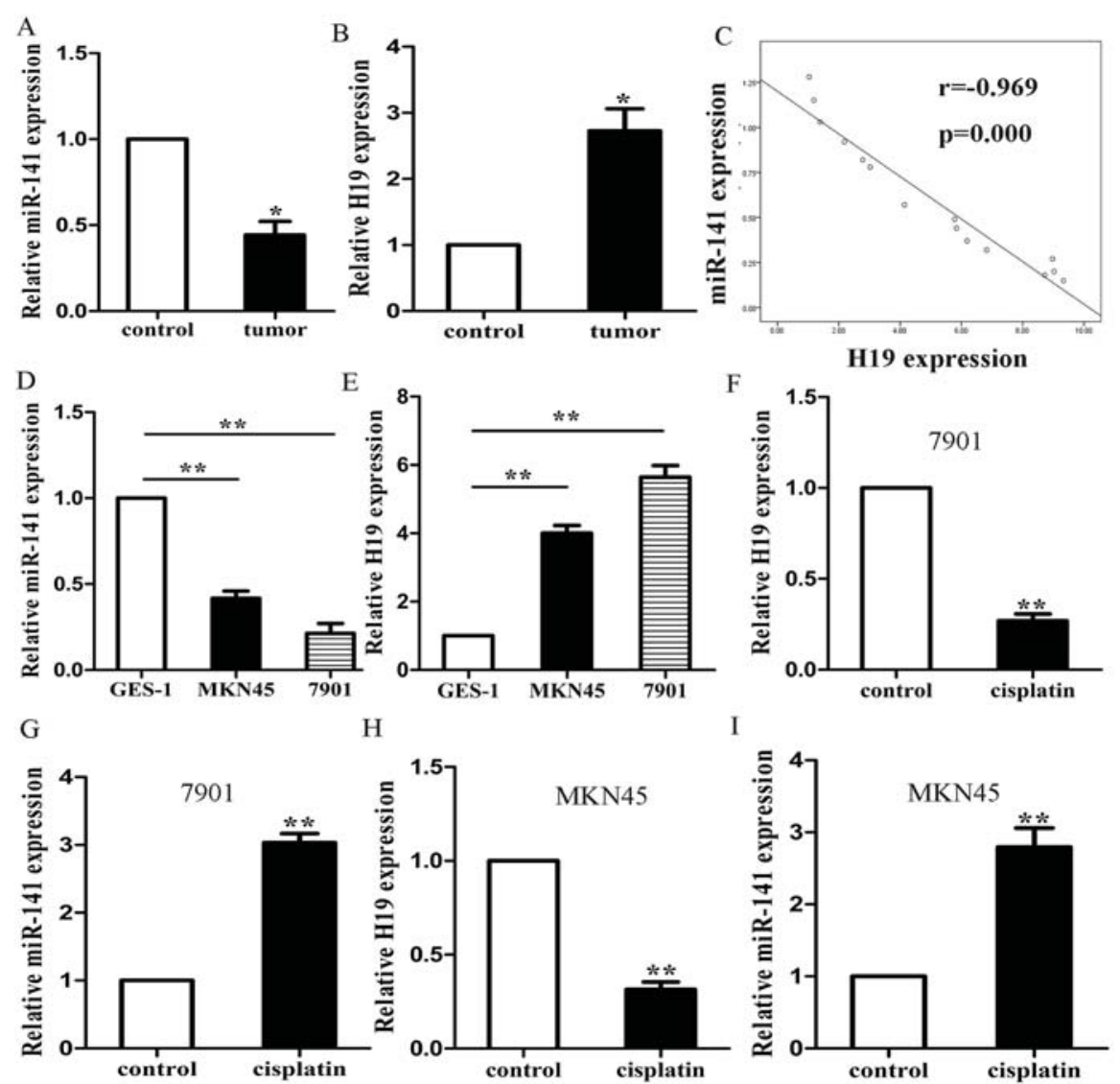

Fig. 1. Inverse expression between miR-141 and H19 in GC tissues and cells. Relative expression of H19 (A) and miR-141 (B) in gastric cancer tissues was analyzed by real-time PCR and was normalized to normal tissues. (C) a statistically significant inverse correlation between miR-141 and H19 in GC specimens (Spearman's correlation analysis, r=-0.969; p=0.000). Relative expression of H19 (D) and miR-141 (E) in gastric cancer tissues was analyzed by real-time PCR and was normalized to immortalized GES-1 cell. Cells were transfected with miR-141 mimics for 2 days and miR-141 (F) and H19 (G) expression was analyzed by real-time PCR and normalized to control. (H) Effect of cisplatin on H19 and miR-141 expression in GC cells. Cells were treated with $10 \mathrm{ug} / \mathrm{ml}$ cisplatin for 4 days. H19 and miR-141 expression was analyzed by real-time PCR and was normalized to that of the control.

cells. MTT assays showed that miR-141 inhibited proliferation of 7901 and MKN45 cells by about $40 \%$. We then transiently transfected cells with miR-141 inhibitor or inhibitor negative control and found that miR-141 inhibitor increased proliferation of cells by about $20 \%$ at 96 h (Fig. 2C). These results indicated that miR-141 significantly inhibits cell proliferation.

Since knock-down of H19 suppressed cell proliferation, we performed apoptosis assays using flow cytometry with Annexin-V. We found that H19 siRNA increased apoptosis to about 2 times that of controls in 7901 and MKN45 cells (Fig. 2D), demonstrating that H19 reduces apoptosis in these cells. We also performed apoptosis assays with miR-141 mimics/inhibitor transfected cells and observed that miR-141 mimics increased cell apoptosis while miR-141 inhibitor reduces apoptosis compared with controls (Fig. 2E), demonstrating that miR-141 promotes apoptosis in cancer cells.

Next, we performed transwell invasion assay using Matrigel to investigate the effect of transiently-transfected H19 siRNA on the invasive ability of 7901 and MKN45 cells. The results clearly revealed that H19 siRNA decreased cell invasion to about $30 \%$ in cells 


\section{Cellular Physiology Cell Physiol Biochem 2015;36:1440-1452 \begin{tabular}{l|l|l}
\hline DOI: 10.1159/000430309 & (C) 2015 S. Karger AG, Basel
\end{tabular} \begin{tabular}{l|l} 
and Biochemistry Publisned onIIne: July U6, 2015 & www.karger.com/cpb
\end{tabular}

Fig. 2. Antagonistic effect of $\mathrm{H} 19$ and miR-141 on cell proliferation. (A) Relative H19 expression after transient transfection of H19 siRNA. Cells were transiently transfected with 25 nM siRNA control or H19 siRNA. H19 expression at $48 \mathrm{~h}$ of the transfection was analyzed by real-time PCR and was normalized to that of the control. (B) Cell proliferation was measured by MTT assays at the indicated times after transfection of H19 siRNA. (C) Cell proliferation was measured by MTT assays at the indicated times after transfection of miR-141 mimics. (D) Cell proliferation was measured by MTT assays at the indicated times after transfection of miR-141 inhibitor. The cells were stained with AnnexinV-FITC and apoptosis was analyzed by flow cytometry after transfected with H19 siRNA (E) or miR-141 mimics or inhibitor (F).

compared with control (Fig. 3A). We also performed transwell invasion assay using Matrigel to investigate the effect of transiently transfected miR-141 inhibitor (Fig. 3B) or miR-141 mimic (Fig. 3C) on the invasive ability of cancer cells. The results show that miR-141 reduced invasion and miR-141 inhibitor increased invasion compared to controls. These results show the opposing effects of $\mathrm{H} 19$ and miR-141 in cell proliferation and invasion.

\section{MiR-141 binds to and suppresses $H 19$ expression}

We examined the seed sequence of miR-141 in H19 and found a predicted binding site for miR-141 (Fig. 4A). We cloned the putative miR-141 target binding sequence into a luciferase construct. Luciferase reporter assays with miR-141 overexpressing cells showed that miR-141 repressed luciferase activity (Fig. 4B). Mutation of the putative miR-141 target sites decreased the response to miR-141, indicating that miR-141 binds to H19 in a sequence specific manner. 


\section{Cellular Physiology Cell Physiol Biochem 2015;36:1440-1452 \begin{tabular}{l|l}
\hline DOI: 10.1159/000430309 & O 015 S. Karger AG, Basel
\end{tabular} and Biochemistry Publisned onine: July U6, 2015 www.karger.com/cpb

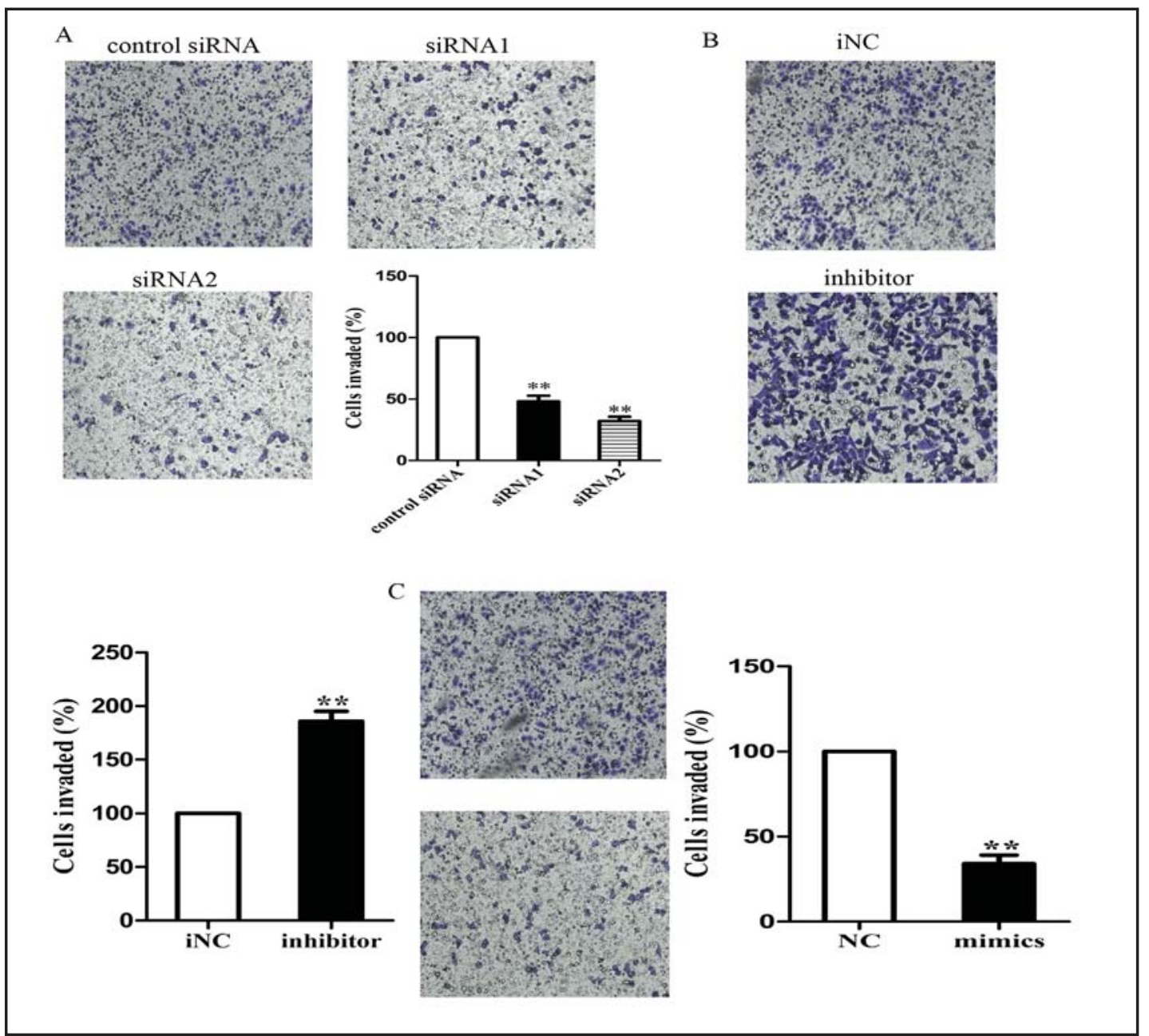

Fig. 3. Antagonistic effect of H19 siRNA and miR-141 on cell invasion. Cells were transiently transfected with either $25 \mathrm{nM}$ siRNA control or H19 siRNA (A) or miR-141 mimics or inhibitor (B) for $48 \mathrm{~h}$. The cells were harvested and subjected to transwell invasion assay. The values are normalized to those of control. Representative images of the invaded cells are shown in the right panel.

Fig. 4. miR-141 targets H19. (A) miR-141 binding sequence in H19. The bold letters in H19 sequence are mutated. (B) Cells in 24well plates were transiently transfected with $25 \mathrm{nM} \mathrm{NC}$ or miR-141 control for $8 \mathrm{~h}$, followed by transient transfection with $25 \mathrm{ng}$ control reporter plasmid or 3'UTR plasmids for 48 h. 3'UTR reporter activity was measured by luciferase assay and normalized to activity of Renilla luciferase.

\section{${ }^{\text {A }}$ WT H19 5'...GCGGAGAGGGCCCACAGUGGA... |||||| hsa-miR-141: 3'...GGUAGAAAUGGUCUGUCACAA5' MUT H19 5' GCGGAGAGGGCCCGACAGUGA...3'}

B

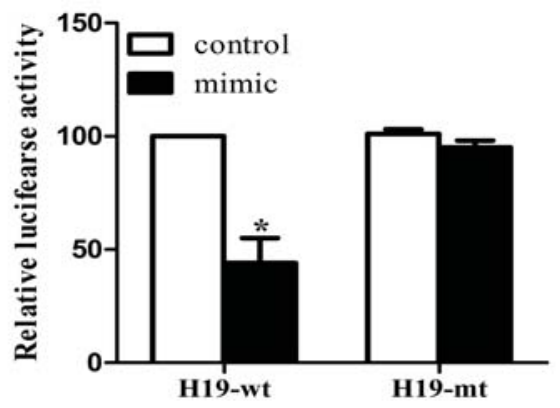




\section{Cellular Physiology Cell Physiol Biochem 2015;36:1440-1452 \begin{tabular}{l|l|l} 
DOI: 10.1159/000430309 & (c) 2015 S. Karger AG, Basel
\end{tabular} \begin{tabular}{l|l} 
and Biochemistry Publisned onIIne: July U6, 2015 & www.karger.com/cpb
\end{tabular}

Fig. 5. $\operatorname{miR}-141$ regulates H19 target genes. Cells were transfected with 25 nM control siRNA or H19 siRNA or 25 nM negative control or miR-141 mimics. (A) After 48-72 $\mathrm{h}$ transfection, mRNA and miRNA expression was analyzed by real-time PCR and was normalized to that of the control. (B) After $96 \mathrm{~h}$ transfection, protein expression was analyzed by western blot.
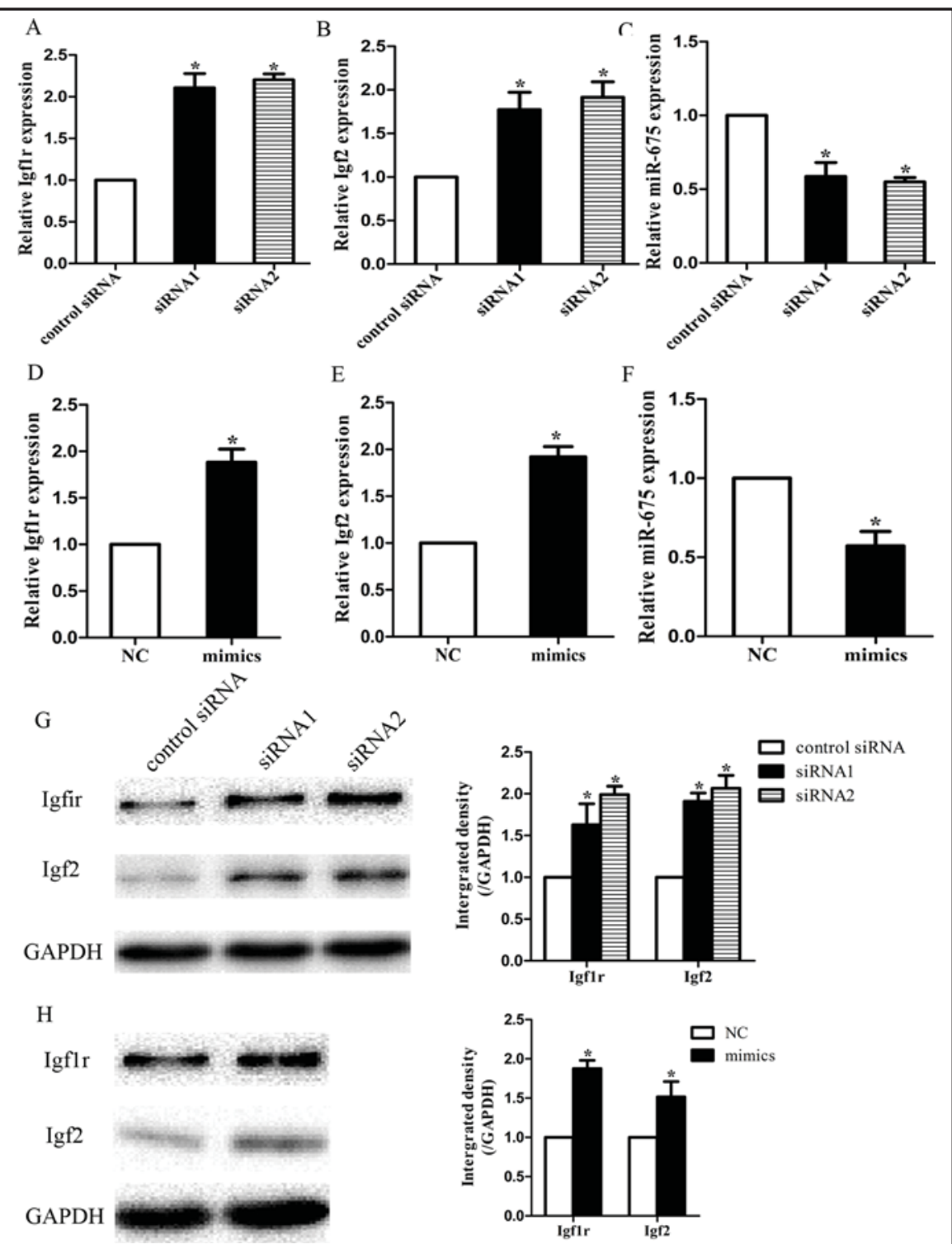
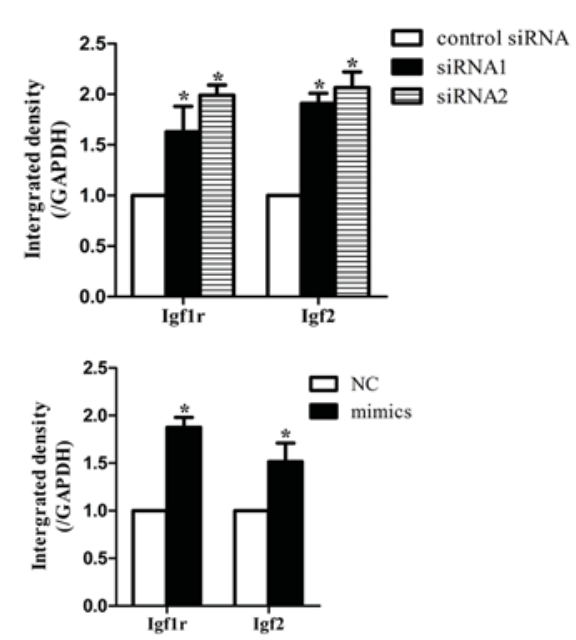

MiR-141 regulates $H 19$ target genes

H19 has been reported to induce miR-675 and to repress Igf1r and Igf2 expression. We examined mRNA and protein expression levels after transfection of H19 siRNA or miR141 to examine whether miR-141 regulates H19 target genes. We found that H19 siRNA and miR-141 reduced miR-675 expression and induced Igf1r and Igf2 expression significantly, including mRNA and protein expression (Fig. 5).

\section{MiR-141 inhibitor restores H19 siRNA function}

To examine if the effects of miR-141 on cell proliferation is mediated by H19, we cotransfected cells with H19 siRNA and miR-141 inhibitor. MiR-141 inhibitor transfection decreased miR-141 expression and H19 siRNA transfection decreased H19 expression. Cotransfection of miR-141 inhibitor and H19 siRNA showed that miR-141 inhibitor increased H19 expression repressed by H19 siRNA significantly (Fig. 6A and B).

We also examined miR-675, Igf1r and Igf2 expression which are regulated by H19 after co-transfection of H19 siRNA and miR-141 inhibitor in 7901 cells. MiR-141 inhibitor induced and H19 siRNA reduced miR-675. Co-transfection of miR-141 inhibitor and H19 


\section{Cellular Physiology Cell Physiol Biochem 2015;36:1440-1452 \begin{tabular}{c|c|c|}
\hline DOI: 10.1159/000430309 & (O 2015 S. Karger AG, Bas
\end{tabular} \\ Zhou et al.: MiR-141 and H19 Regulation in GC}

Fig. 6. MiR-141 inhibitor restores $\mathrm{H} 19$ siRNA function. Cells were co-transfected with $25 \mathrm{nM}$ control siRNA or H19 siRNA and $25 \mathrm{nM}$ negative control or miR-141 inhibitor. MiR-141 inhibitor restores miR675 expression level which is suppressed by H19 siRNA. MiR141 inhibitor inhibits Igf1r and Igf2 expression which is induced by H19 siRNA.

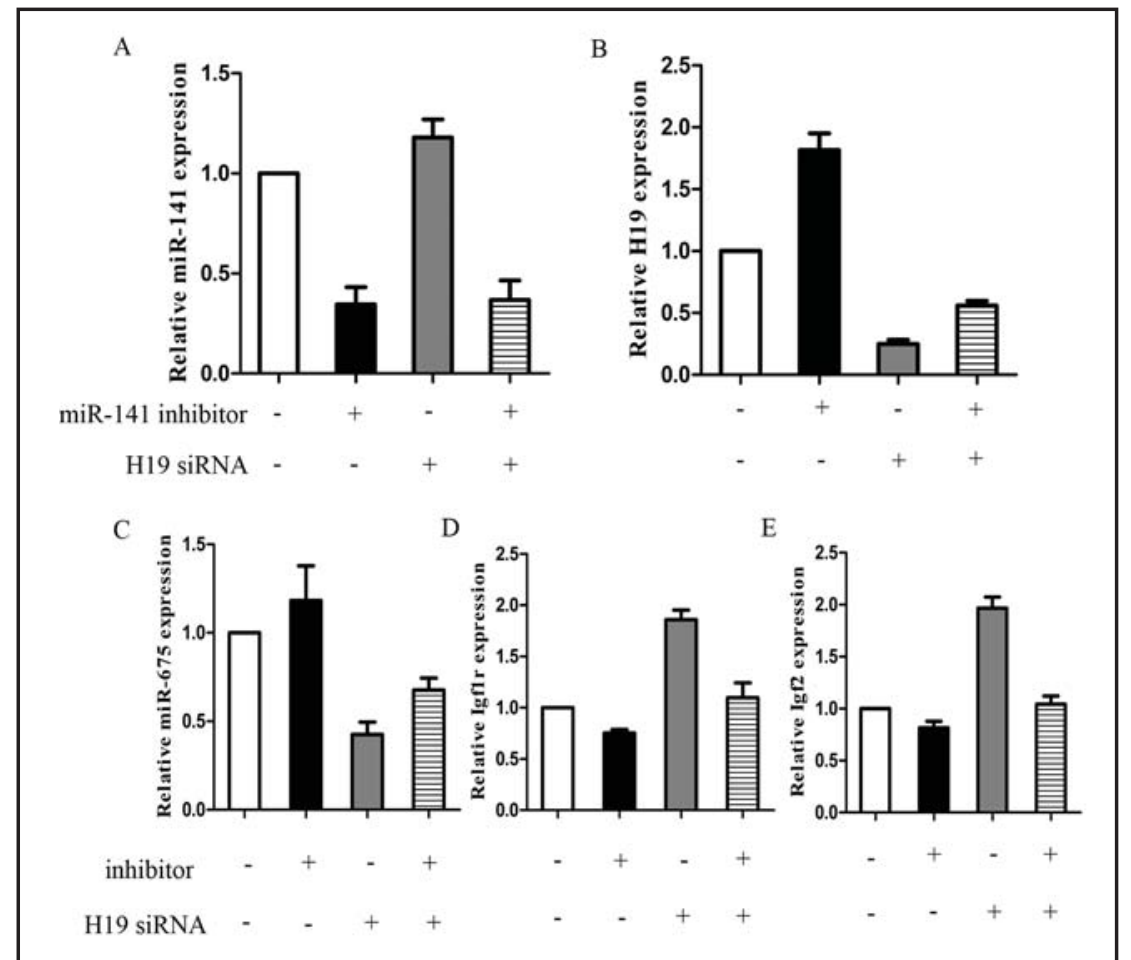

Fig. 7. MiR-141 inhibits H19 function. Cells were co-transfected with $25 \mathrm{nM}$ H19 expression plasmid or control and 25 nM negative control or miR-141 mimics. MiR-141 inhibits miR675 expression level which is induced by H19 transfection. MiR-141 restores Igf1r and Igf2 expression which is repressed by $\mathrm{H} 19$ transfection.

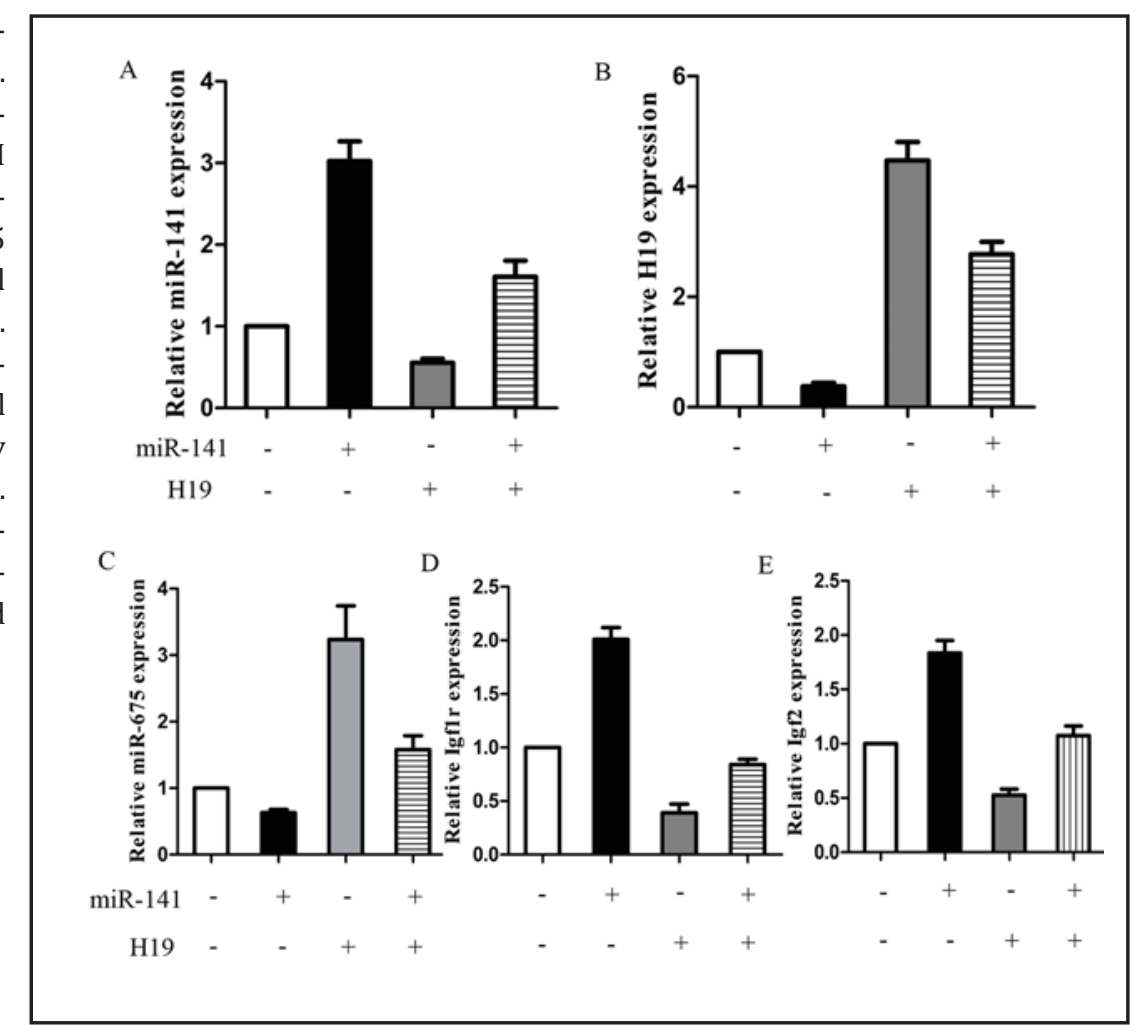

siRNA showed that miR-141 inhibitor restored the suppression of miR-675 by H19 siRNA (Fig. 6C). Inversely, miR-141 inhibitor reduced and H19 siRNA induced Igf1r and Igf2. Cotransfection of miR-141 inhibitor and H19 siRNA showed that miR-141 inhibitor inhibited the up-regulation of Igf1r (Fig. 6D) and Igf2 (Fig. 6E) by H19 siRNA. Taken together, these results indicate that $\mathrm{H} 19$ mediates miR-141 function in these cells. 


\section{Cellular Physiology Cell Physiol Biochem 2015;36:1440-1452 \begin{tabular}{l|l|l}
\hline DOI: 10.1159/000430309 & (c) 2015 S. Karger AG, Basel
\end{tabular} \begin{tabular}{l|l} 
and Biochemistry Publisned on Inne: July 06, 2015 & www.karger.com/cpb
\end{tabular}}

Fig. 8. H19 regulates RNA processing enzyme and miRNA target. Drosha (A) or Dicer (B) expression was measured after cells transfected with H19 siRNA or vector. Cells were transfected with $25 \mathrm{nM}$ control siRNA or H19 siRNA (C) or 6 nM negative control or miR-141 mimics (D). After $72 \mathrm{~h}$ transfection, ZEB1 mRNA was analyzed by real-time PCR and was normalized to that of the control. (E) After $96 \mathrm{~h}$ transfection, ZEB1 protein expression was analyzed by western blot. (F) miR141 inhibits ZEB1 induced by H19. Cells in 6-well plates were co-transfected with 200 ng control plasmid (pcDNA3.1(+)) or H19 expression plasmid (pcDNA3.1(+) -H19) and $6 \mathrm{nM}$ negative control or miR141 mimics. After $72 \mathrm{~h}$ transfection, ZEB1 mRNA expression was analyzed by real-time PCR and was normalized to that of the control.
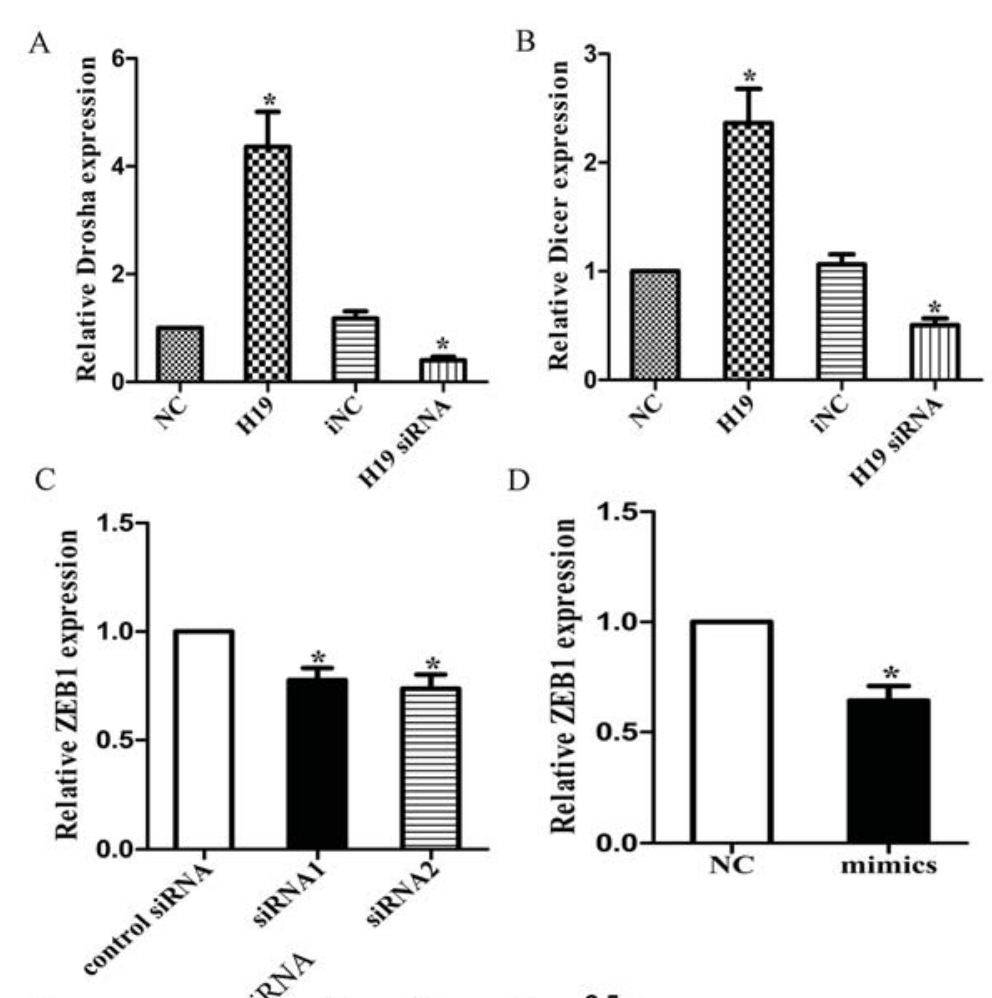

E

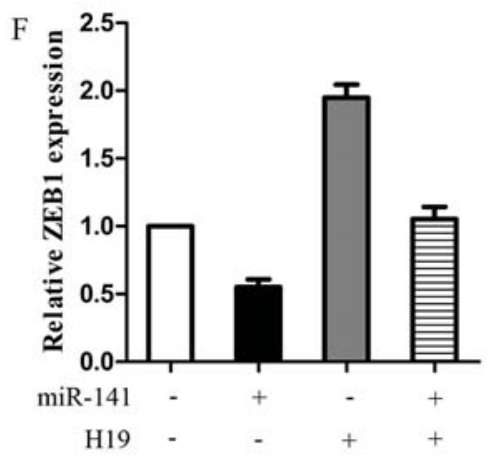

MiR-141 suppresses H19 function

We co-transfected cells with H19 expression plasmid and miR-141 and investigated whether miR-141 suppresses the ectopic H19 expression and function. MiR-141 transfection increased miR-141 expression and H19 transfection increased H19 expression. MiR-141 significantly decreased the ectopic H19 expression (Fig. 7A and B).

We also examined miR-675, Igf1r and Igf2 expression which are regulated by $\mathrm{H} 19$ after co-transfection of miR-141 and H19 in 7901 cells. MiR-141 reduced and H19 induced miR675 expression (Fig. 7C). Co-transfection of miR-141 and H19 showed that miR-141 inhibited the up-regulation of miR-675 by H19. Inversely, miR-141 induced and H19 reduced Igf1r and Igf2. Co-transfection of miR-141 and H19 showed that miR-141 restored the suppression of Igf1r and Igf2 by H19 (Fig. 7D and E). These results also indicate that miR-141 regulated H19 targeted genes expression.

$H 19$ regulates $R N A$ processing enzyme and miRNA target

H19 has a broad effect on miR maturation through interaction with RNA processing enzymes such as DROSHA and DICER. We found that H19 over-expression could significantly up-regulate DICER and DROSHA expression, while H19 knockdown down-regulate their 


\section{Cellular Physiology Cell Physiol Biochem 2015;36:1440-1452 \begin{tabular}{l|l} 
and Biochemistry Publisned onlnne: July 06, 2015 & $\begin{array}{l}\text { D 2015 S. Karger AG, Basel } \\
\text { www.karger.com/cpb }\end{array}$ \\
\hline
\end{tabular} \\ Zhou et al.: MiR-141 and H19 Regulation in GC}

expression (Fig. 8A and B). MiR-141 has been reported to target and repress ZEB1. We examined ZEB1 mRNA and protein expression levels after transfection of H19 siRNA or miR141 and found that H19 siRNA and miR-141 reduced ZEB1 expression in 7901 cells (Fig. 8C, D and E). We also co-transfected cells with miR-141 and H19 expression plasmid and investigated whether miR-141 suppresses ZEB1 induced by H19. We found that miR-141 over-expression decreased ZEB1 while H19 overexpression induced ZEB1 (Fig. 8F). Cotransfection of miR-141 and a H19 expression plasmid showed that miR-141 suppressed ZEB1 induced by H19, suggesting that H19 regulates the miR-141 target gene ZEB1.

\section{Discussion}

NcRNAs, with limited protein-coding capacity, are often expressed in a disease-, tissue- or developmental stage-specific manner, indicating specific functions for lncRNAs in development and diseases and making these molecules attractive therapeutic targets. A growing number of recent papers have revealed that ncRNAs could compete with MREs of mRNA and thus affect gene targets expression [15]. However, the exact role of miRNA and IncRNA interactions in the tumorigenesis of GC remains largely unknown. Understanding the interaction between miRNA and IncRNA would facilitate the development of miRNA/lncRNA based diagnostics and therapeutics against cancers. In this present study, we demonstrated that miR-141 expression was down-regulated in GC tissues while H19 expression was upregulated. Pearson analysis showed that a significant inverse correlation between H19 and miR-141. Besides, we also showed for the first time that up-regualting of miR-141 exerted tumor-suppressive functions in human GC by knockdown of H19 and vice versa.

MiRNAs were found to be dysregulated in several human cancers including GC [16-18]. Han reported that miR-29c acts as a tumor suppressor in GC by directly targeting ITGB1 [16]. Loss of miR-29c expression is an early event in the initiation of gastric carcinogenesis and may serve as a diagnostic and therapeutic biomarker for patients with GC. H. pylori CagA induces aberrant epigenetic silencing of let-7 expression, leading to Ras upregulation, and thus lead to GC [17]. Our previous study showed that miR-141 acted as a tumor suppressor in human GC by targeting signal transducer and activator of transcription 4 (STAT4) [19]. Mei et al [20] showed that miR-141 expression was significantly up-regulated in NSCLC tissues, and its overexpression accelerated NSCLC cell proliferation in vitro and tumor growth in vivo by targeting PHLPP1 and PHLPP2. The reason for this might be that certain genes may be oncogenic in one cell or tissue type but tumor suppressive in another, depending on the cancer type and cellular context. H19 is transcribed in an untranslated RNA molecule that lacks conserved open reading frames but does have a conserved secondary RNA structure which accumulates in the human placenta and several fetal tissues, and probably plays a pivotal role in embryogenesis and fetal growth and tumor development [21]. Emerging evidences have shown that H19 was overexpressed in many types of cancer including hepatocellular [22], bladder [23], colon [24], and breast cancer [25]; however, the underlying role and mechanism of H19 involved in GC remains unclear. Recently, H19 was reported to act as a sponge to antagonize miRNAs, for example, let-7. Kallen et al [26] found that H19 harbors both canonical and noncanonical binding sites for the let-7 family of microRNAs, which plays important roles in development, cancer, and metabolism. Shi et al [27] suggested that lncRNA H19 and its derivate miR-675 were positively correlated with glioma grade, and H19 regulated glioma cell invasion by deriving miR-675.

In the present study, we investigated both roles of miR-141 and H19 in GC. First, we tested the expression of miR-141 and H19 in GC tissues and cells. We also identified the functions of miR-141 and H19 in gastric carcinoma cells by applying gain and loss-offunction approaches. The results demonstrated that H19 was up-regulated in GC tissues and cells while miR-141 was down-regulated. H19 up-regulation and miR-141 downregulation correlated with proliferation, migration and invasion of GC cells. Additionally, H19 suppression and miR-141 overexpression led to the promotion of gastric cell apoptosis. 


\section{Cellular Physiology Cell Physiol Biochem 2015;36:1440-1452

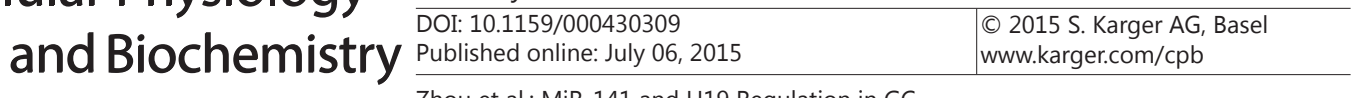

These findings suggested that $\mathrm{H} 19$ and miR-141 played a direct role in the modulation of multiple oncogenic properties and GC progression, stimulating new research directions and therapeutic options considering H19 and miR-141 as novel markers in GC.

Inspired by the 'competitive endogenous RNAs' regulatory network and emerging evidence that suggests that ncRNAs may participate in this regulatory circuitry, we hypothesized that H19 and miR-141 may also serve as ceRNAs in GC. In support of this notion, we employed bioinformatics analysis and luciferase assays to validate the direct binding ability of miR-141 and H19. As expected, we discovered miR-141 could form complementary base pairing with $\mathrm{H} 19$ and induce translational repression of a RLuc-H19 reporter gene. Taken together, these data are consistent with our hypothesis and indicate that H19 may interact with miR-141 to link miR-141 and the post-transcriptional network in gastric pathogenesis.

Next, we examined the role of miR-141 mimic or inhibitor on H19 expression level and $\mathrm{H} 19$ targets. We focused on the target genes Igf1r and Igf2 as they are were previously reported to be repressed by $\mathrm{H} 19$. After we transfecting with miR-141 mimic, the target genes were significantly up-regulated as $\mathrm{H} 19$ was inhibited by miR-141 overexpression and thus H19 could not repress Igf1r and Igf2 expression. On the contrary, when cells tranfected with miR-141 inhibitor, the target genes were significantly down-regulated and H19 was overexpressed. Besides, we also examined the role of H19 on miR-141 and its target gene ZEB1 level. The results were similar, which showed that H19 could compete with miRNA and affect ZEB1 expression.

However, in the present study, we only investigated one pair of miRNA and lncRNA. The ceRNA activity of H19 may sequester a handful of miRNAs at once, while one miRNA is also capable of controlling multiple genes. We also hypothesize that there may be many other lncRNAs or miRNAs that function as ceRNAs to regulate expression of key genes in GC. Thus, the identification of these ceRNAs will undoubtedly enhance our knowledge of how ncRNAs function, allowing us to better understand the pathogenesis and development of GC and ultimately facilitate the development of ncRNA-directed diagnostics and therapeutics against this deadly disease.

\section{Acknowledgement}

This work was supported by National Natural Science Foundation of China (No. 81270476), the Priority Academic Program Development of Jiangsu Higher Education Institutions (JX10231801) and Jiangsu postgraduate scientific research and innovation projects (CXZZ13_0574).

\section{Disclosure Statement}

The authors declare no conflict of interest.

\section{Reference}

1 Li PF, Chen SC, Xia T, Jiang XM, Shao YF, Xiao BX, Guo JM: Non-coding RNAs and gastric cancer. World J Gastroenterol 2014;20:5411-5419.

-2 Bierhoff H, Postepska-Igielska A, Grummt I: Noisy silence: non-coding RNA and heterochromatin formation at repetitive elements. Epigenetics 2014;9:53-61.

-3 Ørom UA, Shiekhattar R: Long noncoding RNAs usher in a new era in the biology of enhancers. Cell 2013;154:1190-1193.

4 Wang QX, Zhu YQ, Zhang H, Xiao J: Altered MiRNA expression in gastric cancer: a systematic review and meta-analysis. Cell Physiol Biochem 2015;35:933-944.

-5 Poliseno L, Salmena L, Zhang J, Carver B, Haveman WJ, Pandolfi PP: A coding-independent function of gene and pseudogene mRNAs regulates tumour biology. Nature 2010;465:1033-1038. 


\section{Cellular Physiology Cell Physiol Biochem 2015;36:1440-1452

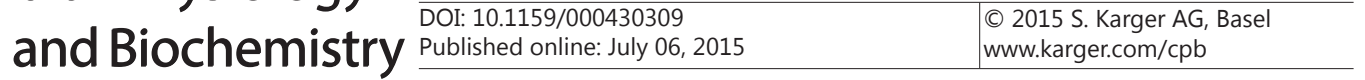

Zhou et al.: MiR-141 and H19 Regulation in GC

-6 Paci P, Colombo T, Farina L: Computational analysis identifies a sponge interaction network between long non-coding RNAs and messenger RNAs in human breast cancer. BMC Syst Biol 2014;8:83.

7 Chiu HS, Llobet-Navas D, Yang X, Chung WJ, Ambesi-Impiombato A, Iyer A, Kim HR, Seviour EG, Luo Z, Sehgal V, Moss T, Lu Y, Ram P, Silva J, Mills GB, Califano A, Sumazin P: Cupid simultaneous reconstruction of microRNA-target and ceRNA networks. Genome Res 2015;25:257-267.

8 Legnini I, Morlando M, Mangiavacchi A, Fatica A, Bozzoni I: A feedforward regulatory loop between HuR and the long noncoding RNA linc-MD1 controls early phases of myogenesis. Mol Cell 2014;53:506-514.

-9 Kim EJ, Baik GH: Review on gastric mucosal microbiota profiling differences in patients with chronic gastritis, intestinal metaplasia, and gastric cancer. Korean J Gastroenterol 2014;64:390-393.

10 Cui Y, Chen J, He Z, Xiao Y: SUZ12 depletion suppresses the proliferation of gastric cancer cells. Cell Physiol Biochem 2013;31:778-784.

11 Jia W, Chen W, Kang J: The functions of microRNAs and long non-coding RNAs in embryonic and induced pluripotent stem cells. Genomics Proteomics Bioinformatics 2013;11:275-283.

12 Park SM, Gaur AB, Lengyel E, Peter ME: The miR-200 family determines the epithelial phenotype of cancer cells by targeting the E-cadherin repressors ZEB1 and ZEB2. Genes Dev 2008;22:894-907.

-13 Zuo QF, Zhang R, Li BS, Zhao YL, Zhuang Y, Yu T, Gong L, Li S, Xiao B, Zou QM: MicroRNA-141 inhibits tumor growth and metastasis in gastric cancer by directly targeting transcriptional co-activator with PDZ-binding motif, TAZ. Cell Death Dis 2015;6: e1623.

- 14 Koutsaki M, Spandidos DA, Zaravinos A: Epithelial-mesenchymal transition-associated miRNAs in ovarian carcinoma, with highlight on the miR-200 family: prognostic value and prospective role in ovarian cancer therapeutics. Cancer Lett 2014;351:173-181.

15 Shi X, Sun M, Liu H, Yao Y, Song Y: Long non-coding RNAs: a new frontier in the study of human diseases. Cancer Lett 2013;339:159-166.

-16 Han TS, Hur K, Xu G, Choi B, Okugawa Y, Toiyama Y, Oshima H, Oshima M, Lee HJ, Kim VN, Chang AN, Goel A, Yang HK: MicroRNA-29c mediates initiation of gastric carcinogenesis by directly targeting ITGB1. Gut 2015;64:203-214.

17 Hayashi Y, Tsujii M, Wang J, Kondo J, Akasaka T, Jin Y, Li W, Nakamura T, Nishida T, Iijima H, Tsuji S, Kawano S, Hayashi N, Takehara T: CagA mediates epigenetic regulation to attenuate let-7 expression in Helicobacter pylori-related carcinogenesis. Gut 2013;62:1536-1546.

-18 Zhang D, Xiao YF, Zhang JW, Xie R, Hu CJ, Tang B, Wang SM, Wu YY, Hao NB, Yang SM: miR-1182 attenuates gastric cancer proliferation and metastasis by targeting the open reading frame of hTERT. Cancer Lett 2015;360:151-159.

19 Zhou X, Xia Y, Su J, Zhang G: Down-regulation of miR-141 induced by helicobacter pylori promotes the invasion of gastric cancer by targeting STAT4. Cell Physiol Biochem 2014;33:1003-1012.

20 Mei Z, He Y, Feng J, Shi J, Du Y, Qian L, Huang Q Jie Z: MicroRNA-141 promotes the proliferation of nonsmall cell lung cancer cells by regulating expression of PHLPP1 and PHLPP2. FEBS Lett 2014;588:30553061.

-21 Ratajczak MZ: Igf2-H19, an imprinted tandem gene, is an important regulator of embryonic development, a guardian of proliferation of adult pluripotent stem cells, a regulator of longevity, and a 'passkey' to cancerogenesis. Folia Histochem Cytobiol 2012;50:171-179.

22 Wu J, Qin Y, Li B, He WZ, Sun ZL: Hypomethylated and hypermethylated profiles of H19DMR are associated with the aberrant imprinting of IGF2 and H19 in human hepatocellular carcinoma. Genomics 2008;91:443450.

23 Luo M, Li Z, Wang W, Zeng Y, Liu Z, Qiu J: Long non-coding RNA H19 increases bladder cancer metastasis by associating with EZH2 and inhibiting E-cadherin expression. Cancer Lett 2013;333:213-221.

24 Tsang WP, Ng EK, Ng SS, Jin H, Yu J, Sung JJ, Kwok TT: Oncofetal H19-derived miR-675 regulates tumor suppressor RB in human colorectal cancer. Carcinogenesis 2010; 31:350-358.

25 Barnholtz-Sloan JS, Shetty PB, Guan X, Nyante SJ, Luo J, Brennan DJ, Millikan RC: FGFR2 and other loci identified in genome-wide association studies are associated with breast cancer in African-American and younger women. Carcinogenesis 2010;31:1417-1423.

26 Kallen AN, Zhou XB, Xu J, Qiao C, Ma J, Yan L, Lu L, Liu C, Yi JS, Zhang H, Min W, Bennett AM, Gregory RI, Ding Y, Huang Y: The imprinted H19 lncRNA antagonizes let-7 microRNAs. Mol Cell 2013;52:101-112.

-27 Shi Y, Wang Y, Luan W, Wang P, Tao T, Zhang J, Qian J, Liu N, You Y: Long non-coding RNA H19 promotes glioma cell invasion by deriving miR-675. PLoS One 2014;9:e86295. 